\title{
Exercise for lower limb osteoarthritis: systematic review incorporating trial sequential analysis and network meta-analysis
}

Correspondence to: D van der Windt d.van.der.windt@keele.ac.uk

Extra material supplied by the author (see http://www.bmj.com/content/347/bmj.f5555?tab=related\#webextra)

Appendix 1: Search strategies for Medline and Embase

Appendix 2: Characteristics of randomised controlled trials included in network meta-analysis

Appendix 3: Risk of bias summary and graph

Appendix 4: Trial sequential analysis of cumulative meta-analysis

Appendix 5: Network of eligible exercise intervention comparisons for pain

Appendix 6: Pain and physical function treatment effect estimates of all comparisons according to network meta-analysis 
hospital care) and indirect costs (such as loss in productivity). ${ }^{45}$ Between 1999 and 2000 in the United Kingdom, about 36 million working days were lost because of osteoarthritis alone, leading to an estimated $£ 3.2 \mathrm{bn}(€ 3.8 \mathrm{bn}, \$ 5.1 \mathrm{bn})$ in productivity losses, with the total cost to the UK economy being estimated at $1 \%$ of gross national product per year. ${ }^{1}$ In the United States, the estimated incremental cost of medical care expenditures and earnings losses for people with arthritis or other rheumatological conditions was $\$ 128$ billion ( $£ 80.5 \mathrm{bn}, € 95.8 \mathrm{bn}$ ) in $2003 .{ }^{6}$ In Canada, time lost from employment and leisure by people with disabling hip or knee osteoarthritis and their unpaid caregivers has been estimated at $\$ C 12200$ ( $£ 7400, € 8800$, US\$11 800) per person per year.

The main goal of treatment for patients with osteoarthritis is to relieve the common symptoms of joint pain and improve everyday physical function. ${ }^{8}$ Current international guidelines recommend therapeutic exercise (land or water based) as "core" 9-12 and effective management, given its beneficial effects, ${ }^{8}{ }^{13-16}$ ease of application, few adverse effects, and relatively low costs. Regular exercise can reduce physical impairments and improve participation in social, domestic, occupational, and recreational activities. ${ }^{14}$ Additional benefits of exercise include improvements in mobility, risk of falls, body weight, mental health, and metabolic abnormalities. ${ }^{14}$ Recent guidance recommends both strengthening and aerobic exercise, ${ }^{1}$ but there are multiple other approaches to exercise such as stretching/flexibility, endurance training, aquatic exercise, and increasing general physical activity.

Several systematic reviews, including meta-analyses, have examined the effectiveness of exercise interventions for osteoarthritis. ${ }^{8{ }^{13-15} 17-21}$ Since these reviews were published, many new trials have been conducted. Previous reviews have primarily focused on pairwise comparisons of the different exercise interventions within individual trials. One recent systematic review and network meta-analysis compared the effectiveness of acupuncture with other relevant physical treatments for alleviating pain from osteoarthritis. ${ }^{22}$ To our knowledge no review has yet compared different exercise approaches relative to each other by using network meta-analysis in which all interventions are compared equally by drawing on both direct evidence (comparing treatments within the same trial) and indirect evidence (comparing treatments from different trials). This approach deals with a critical research gap highlighted by recent Cochrane Reviews, ${ }^{813}$ which is the need for further studies to help provide evidence of the optimal types of exercise interventions and support decision making by patients, clinicians, and service commissioners. In this review, we first examined whether the required amount of information has been reached to confidently conclude that exercise is more effective than no exercise and that future trials need no longer examine this question. Secondly, we conducted a comprehensive synthesis using network meta-analysis methods to compare the effectiveness of different exercise interventions for pain and function in patients with lower limb osteoarthritis and to support evidence based recommendations regarding the content of these exercise programmes.

\section{Methods}

\section{Information sources and search strategy}

An information specialist developed the search strategy with input from clinicians and academics in the reviewing team. Exercise interventions were defined as any type of therapeutic exercise (land or water based), regardless of content, duration, frequency, or intensity. We searched Medline, Embase,
CINAHL, AMED, HMIC (Health Management Information Consortium), Cochrane Database of Systematic Reviews Cochrane Controlled Clinical Trials (CENTRAL), DARE (Database of Reviews of Effectiveness), NHS EED (Economic Evaluations Database), and Web of Science from inception to March 2012. Appendix 1 shows the full search strategies for Medline and Embase. The Cochrane highly sensitive search was used to identify randomised controlled trials. No language restrictions were applied. The bibliographies of relevant review articles and selected articles were examined for additionally potentially relevant trials.

\section{Study selection}

We evaluated each identified study against the following predetermined selection criteria:

- Study population: adults with an established clinical or radiographic diagnosis of knee or hip osteoarthritis according to accepted criteria ${ }^{23}$

- Intervention: any therapeutic exercise intervention (land or water based), regardless of content, duration, frequency, or intensity

- Comparator: other forms of exercise or no exercise control group

- Outcome measure: in agreement with international consensus ${ }^{24}$ regarding the core set of outcome measures for clinical trials in osteoarthritis, the trials needed to include assessment of at least one of self reported pain and function

- Study design: randomised controlled trials. Trials were excluded if they concerned perioperative exercise therapy (immediately before or after surgery) or if intervention groups received identical exercise interventions (that is, no contrast existed between the intervention groups).

\section{Quality assessment}

We used the Cochrane Collaboration's tool for assessing risk of bias for quality assessment of the included trials. ${ }^{25}$ The trials were graded (unclear, high, or low risk of bias) based on sequence generation, allocation concealment, blinding of outcome assessor, incomplete outcome data, and selective outcome reporting.

\section{Study selection and data abstraction}

In pairs, six reviewers (OAU, DAvdW, JLJ, NEF, KSD, ELH) independently evaluated the eligibility and methodological quality of each trial and extracted data. Two reviewers independently classified the exercise interventions, based on three a priori defined characteristics or common aims of exercise interventions in osteoarthritis: to mainly improve strength, flexibility, or aerobic capacity/general health. Discrepancies were resolved by discussion. For each included trial we extracted details on design, sample size, population characteristics (knee osteoarthritis, hip osteoarthritis, or mixed), interventions (land based or aquatic, duration, number of supervised sessions and type of exercise), and outcome assessment (type of outcome measure and length of follow-up) on to a specifically designed electronic form and recorded the results of quality assessments.

\section{Summary measures}

The primary measure of treatment effect was the standardised mean difference (SMD) for pain intensity and function. This is the difference in means between the two groups, divided by the 
pooled standard deviation (SD) of the measurements. A negative value indicates more pain relief or improved function. We calculated change scores from baseline because many of the studies were small and there were significant baseline differences in scores between the treatment groups. ${ }^{13}$ When effect sizes were incompletely reported we contacted the corresponding author or estimated the SD on the basis of the sample size, median, and range, as suggested by Hozo and colleagues ${ }^{26}$ or on the basis of the sample size and $\mathrm{P}$ value. For trials with multiple follow-ups, we used the longest duration reported. When a study reported multiple pain scales, we used the highest on the hierarchy of pain related outcomes as described by Juni and colleagues. ${ }^{27}$ When the SDs of absolute changes from baseline were not available from individual trials, we imputed them as described in detail in the Cochrane Handbook. ${ }^{28}$ In brief, we assumed a correlation of $r=0.5$ between baseline and follow-up to estimate SD for change from baseline. ${ }^{29}$ Using the imputed correlation coefficient values, we thereafter calculated SDs for the change from baseline for the studies with missing SDs. We classed the effect sizes into three categories: $0.2-<0.3$ as small, $0.3-<0.8$ as medium, and $>0.8$ as large..$^{30}$ If possible we used the intention to treat population for analyses. We back transformed effect sizes (SMD) for pain to differences on a $10 \mathrm{~cm}$ visual analogue scale (VAS) based on a median pooled SD of $2.5 \mathrm{~cm}$ reported in large scale trials in osteoarthritis that used a similar visual analogue scale for pain. ${ }^{31}$ Similarly, we back transformed standardised mean differences for function to a standardised Western Ontario and McMaster Universities (WOMAC) disability score ${ }^{32}$ ranging from 0 to 10 on the basis of a median pooled SD of 2.1 units reported in large scale trials. ${ }^{31}$

\section{Trial sequential analysis}

We examined the reliability and conclusiveness of the available evidence using trial sequential analyses (TSA). ${ }^{33-35}$ The sample size required for a reliable and conclusive meta-analysis is at least as large as that of a single optimally powered randomised controlled trial. Therefore, we calculated the sample size (that is, the heterogeneity corrected optimal information size (HOIS)) required to detect or reject a minimal relevant difference of two points on the mean pain relief and function scales in favour of exercise compared with no exercise control. We then used the HOIS to help construct Lan-DeMets sequential monitoring boundaries for our cumulative meta-analyses, ${ }^{36}$ analogous to interim monitoring in a randomised controlled trial, to determine when sufficient evidence had been accrued. We conducted the trial sequential analyses in TSA version $0.9^{37}$ with an intention to maintain an overall $1 \%$ risk of a type I error and $10 \%$ risk of a type II error (power of $90 \%$ ).

\section{Data synthesis and model implementation}

We used random effect Bayesian network meta-analysis (NMA) to compare the relative effectiveness of different exercise interventions..$^{38-41}$ Network meta-analysis is a generalisation of meta-analysis methods that allows comparisons of interventions not compared directly within individual primary trials. We accounted for the correlation between treatment effects induced by three arm trials using the multi-arm trial code in WinBUGS. ${ }^{42}$ We calculated the probability of each exercise intervention being the most effective (first best), the second best, the third best, and so on, and presented the results graphically with rankograms. ${ }^{40}$ Probability values were summarised and reported as surface under the cumulative ranking (SUCRA). ${ }^{40}$ SUCRA $=1$ if an exercise intervention always ranks first and 0 if it always ranks last.
We estimated the consistency between direct evidence (from randomised controlled trials directly comparing different exercise interventions) and indirect evidence by calculating the difference of standardised mean differences for indirect versus direct comparisons whenever indirect estimates could be constructed with a single common comparator. ${ }^{43} \mathrm{We}$ also inspected heterogeneity using Higgins' $\mathrm{I}^{2}$ measure for each pairwise comparison. As we expected that some comparisons would be based on a larger number of trials than others, we calculated the percentage contribution of each estimate in the network on the summary estimates and on the entire network. The results were summarised in contribution plots by using weighted squares representing the percentage contribution of each comparison. ${ }^{44}$

We conducted a sensitivity analysis to examine whether effect estimates would be influenced by the joint investigated in the individual trials. As most trials focused on knee osteoarthritis, in this sensitivity analysis we restricted the network meta-analysis to knee osteoarthritis trials only. The number of trials focusing on hip osteoarthritis, or including patients with hip, knee, or other lower limb joints, was too small to carry out a separate network meta-analysis. Finally, we used network meta-regression analysis to investigate whether potential heterogeneity could be explained by differences in year of publication, ${ }^{43}$ number of supervised sessions (as a measure of treatment intensity), and duration of follow-up. The meta-regression was performed by allowing for a common treatment-covariate interaction for each exercise intervention to no exercise control in the network meta-analysis. ${ }^{45}$

The network meta-analyses were conducted with a Bayesian Markov chain Monte Carlo method and fitted in Bayesian software, WinBUGS. ${ }^{42}$ Two Markov chains were run simultaneously with different arbitrarily chosen initial values. Convergence to a stable solution was checked by viewing plots of the sampled simulations and use of the Brooks-Gelman-Rubin diagnostic tool (available on request). ${ }^{46}{ }^{47}$ Convergence was found to be adequate after we ran 50000 samples for both chains. These samples were then discarded as "burn-in" and posterior summaries are based on 100000 subsequent simulations. All results are reported as posterior medians of standard mean differences with corresponding $95 \%$ credible intervals (CrIs). Credible intervals are the Bayesian equivalent of classic confidence intervals. A 95\% credible interval can be interpreted as there being a $95 \%$ probability that the parameter takes a value in the specified range.

\section{Results}

\section{Study selection and characteristics}

The literature search yielded 3796 articles, from which we selected 177 full text articles for critical reading (fig $1 \Downarrow$ ). Of the 177 articles, 115 did not meet the inclusion criteria and were excluded. Sixty randomised controlled trials ${ }^{21}{ }^{48-107}(8218$ patients) with usable outcome data met the inclusion criteria and were included. Appendix 2 details the characteristics of the included trials. The trials were published between 1989 and 2012. The maximum length of follow-up ranged from 4 weeks to 79 weeks (median 15 weeks). Most of the trials were from the US ( $n=17,28 \%)$, followed by the UK $(n=9,15 \%)$ and Australia $(n=8,13 \%)$. Trials recruited participants mostly from local communities. Most of the trials recruited patients with knee osteoarthritis ( $\mathrm{n}=44,73 \%)$, two investigated hip osteoarthritis (4\%), and 14 (23\%) recruited a mix of patients with osteoarthritis of the hip, knee, or other joints. 


\section{Risk of bias of included trials}

We assessed risk of bias in all included trials (see appendix 3 for summary and graph). The generation of the allocation sequence was adequate in most trials $(n=42,60 \%)$. Allocation concealment was adequate in almost half of the trials $(n=25$, $42 \%)$. Thirty one trials (52\%) masked outcome assessors to treatment allocation. The potential risk of bias likely to be introduced by incomplete data was high in 10 trials (18\%). The risk of selective reporting bias was low in most trials $(n=53$, $88 \%)$.

\section{Trial sequential analysis}

Trial sequential analysis showed that as of 2002 enough evidence had been accrued to show significant benefit of exercise intervention over no exercise control for both pain and functional improvement (see appendix 4). The cumulative $\mathrm{z}$ curve for pain and function crossed the trial sequential monitoring boundaries, implying that there is firm evidence for a beneficial effect of exercise interventions over no exercise in people with lower limb osteoarthritis.

\section{Network meta-analysis of exercise interventions: pain outcome}

There were 13 comparisons ( 12 exercise interventions plus no exercise controls) in the network of eligible exercise intervention comparisons for pain (see appendix 5). Most trials included a no exercise control group $(\mathrm{n}=54,90 \%)$. The commonest comparison was no exercise control versus strengthening exercise $(n=12,20 \%)$, followed by no exercise control versus combined exercise (flexibility plus strengthening plus aerobic exercise) $(n=10,17 \%)$. No comparison had undue influence or contribution to the effect estimates in the entire network. The weighted percentage contributions of each comparison were fairly equally distributed in the entire network of evidence. Analysis based on direct versus indirect comparisons showed no evidence of inconsistency between direct and indirect evidence in the network, although some comparisons were based on a small number of trials. Table 1 provides information regarding statistical heterogeneity in pairwise comparisons $\left(\mathrm{I}^{2}\right) \Downarrow$. For most comparisons $95 \%$ confidence intervals for statistical heterogeneity were wide and included values suggesting either no or large heterogeneity, which reflects the small number of studies available for most pairwise comparisons.

Figure $2 \Downarrow$ summarises the results of the network meta-analyses for the outcome measure of pain for all trials (regardless of the joint involved). Strengthening exercise only, strengthening plus flexibility, combined strengthening plus flexibility plus aerobic, aquatic strengthening, and aquatic strengthening plus flexibility were significantly more effective than no exercise control (see appendix 6 for pairwise comparisons). The overall difference in pain intensity ( $v$ control) was $-2.03 \mathrm{~cm}$ ( $95 \%$ credible interval -2.82 to $-1.26 \mathrm{~cm}$, large effect size) on a $10 \mathrm{~cm}$ visual analogue scale for strengthening only exercise, $-1.26 \mathrm{~cm}(-2.12$ to -0.40 $\mathrm{cm}$, medium effect size) for flexibility plus strengthening exercise, $-1.74 \mathrm{~cm}(-2.60$ to $-0.88 \mathrm{~cm}$, medium effect size) for flexibility plus strengthening plus aerobic, $-1.87 \mathrm{~cm}(-3.56$ to -0.17 , medium effect size) for aquatic strengthening, and $-1.87 \mathrm{~cm}(-4.11$ to $-0.68 \mathrm{~cm}$, large effect size) for aquatic flexibility plus strengthening exercise. In terms of the cumulative probability of being the overall best exercise intervention for pain in lower limb osteoarthritis, aquatic strengthening plus aerobic flexibility exercise $(81 \%)$ was closely followed by strengthening exercise only $(76 \%)$, and aquatic strengthening plus aerobic exercise (73\%) (fig 2). $\Downarrow$
When we limited the analysis to trials focusing on knee osteoarthritis, the cumulative rankings did not change much (table $2 \Downarrow$ ), but effect estimates tended to be larger compared with the overall analysis, which also included trials focusing on hip osteoarthritis and trials investigating osteoarthritis in any joint. The results of the meta-regression analyses did not show any significant association between exercise effects and either one of the three study level covariates considered (table 2) $\downarrow$. Comparative effect estimates (SMDs) and cumulative rankings of exercise interventions also did not change appreciably in meta-regression analyses when we adjusted for trial publication year, number of supervised sessions, or duration of follow-up (table 2).

\section{Network meta-analysis of exercise interventions: function outcomes}

For function outcomes there seemed to be no evidence of inconsistency between direct and indirect evidence in the network, although the number of trials for some comparisons was small. The combined intervention of strengthening plus flexibility plus aerobic exercise was significantly more effective than no exercise controls (appendix 6). The overall difference in function (versus no control) was -1.32 units (95\% credible interval -2.44 to -0.21 units, medium effect size) on a WOMAC disability scale ranging from 0 to 10 for the combination of strengthening, flexibility, and aerobic exercise. Figure 2 shows that this combination of three types of exercise $(71 \%)$ and aquatic strengthening plus aerobic (71\%) exercises had the highest probability of being the best overall treatment for function. $\Downarrow$

Similar to the analysis of pain, when we limited the network meta-analysis to knee osteoarthritis trials, the cumulative rankings showed little change, although effect estimates were generally slightly larger compared with the overall analysis (table $3 \Downarrow$ ). The meta-regression analyses did not detect any significant association between exercise treatment effects and the three study level covariates considered (table 3). After adjustment for possible differences in these study level factors, however, combined exercise programmes including flexibility, strengthening, and aerobic exercise were no longer significantly more effective than no exercise controls.

There were no significant differences for pairwise comparisons between the different types of exercise, with small to moderate effect sizes for both pain and function (appendix 6). Figure 3 shows the scatterplot of cumulative probabilities of being the most effective exercise intervention for both pain and function, which indicates that it is likely that interventions consisting of a combination of strengthening exercises with aerobic and/or flexibility exercises are most effective. $\Downarrow$

\section{Discussion}

When we applied trial sequential analysis to determine the reliability and conclusiveness of evidence for the effectiveness of exercise interventions over no exercise control, it is clear that as of the year 2002 there was firm evidence of the effectiveness of exercise interventions for pain relief and improvement in function in patients with lower limb osteoarthritis. The totality of evidence, although largely based on trials in knee osteoarthritis shows that further trials of exercise versus no exercise are unlikely to overturn this positive result.

Furthermore, the network meta-analysis showed that there is no significant difference in effect estimates between different types of exercise interventions, which could be partly explained by the small number of studies for several pairwise comparisons. 
However, our data support better results for some exercise interventions. Based on relative effect estimates and cumulative ranking, interventions combining strengthening with flexibility and aerobic exercise (either land or water based) seemed to be the most effective intervention when we considered measures of both pain and function in lower limb osteoarthritis and was the only exercise intervention significantly more effective than no exercise control for both pain and function. The cumulative ranking obtained by the network meta-analysis cannot be considered as conclusive because it was impaired by the lack of significant differences among the exercise interventions. For example, aquatic flexibility plus strengthening exercises occupy the first rank position ( $81 \%$ ) for pain but did not show superiority over any of the other exercise interventions. The lack of significant differences between different types of exercise interventions, however, might be because of the small number of studies contributing evidence to several comparisons in the network.

\section{Study strengths and limitations}

Our study has several strengths and limitations. We performed a comprehensive search of several databases and sources to identify eligible trials, with no language restriction. We reduced potential bias in the conduct of this review by having pairs of reviewers independently scan through the search output, extract data, classify interventions, and assess the methodological quality of each trial. Though our review uniquely aimed to determine if and when sufficient evidence for exercise interventions had been accrued, repeated meta-analysis with accumulating trial data can lead to false positive findings (random errors) if multiple testing is not accounted for. ${ }^{34}$ To minimise random error, we calculated an information size (that is, required meta-analysis sample size) as large as that of an adequately powered trial and applied trial sequential analysis to the meta-analysis. ${ }^{33-35}$ The results of trial sequential analysis can therefore also support decisions regarding the need for and feasibility of future trials. ${ }^{108}$

To our knowledge, this is the first network meta-analysis of exercise for lower limb osteoarthritis. It shows the usefulness of network meta-analysis for comparing different exercise interventions and for evaluating the relative effectiveness of each. Network meta-analysis is particularly relevant to this, given that exercise is a complex and multifaceted intervention and the number of trials comparing the same exercise interventions is small. Results are also likely to be more useful to policy makers, service commissioners, and care providers when they are making choices between multiple alternatives than results from multiple separate pairwise meta-analyses. ${ }^{109}$ Another important strength of the network meta-analysis is that it treats all comparators as separate treatments while gaining statistical power from including all available data. ${ }^{109}$ The Bayesian approach has the additional advantage of being able to provide probability statements for which exercise intervention is the most effective, even when standard methods might determine no significant difference between them. In addition, we calculated alternative rankings (second, third best, etc), because in some cases the best exercise intervention might be unavailable, more costly, or contraindicated in some patients.

Our main aim was to explore the relative effectiveness of three main components of exercise interventions: increasing strength, flexibility, or endurance. We realise that this approach does not allow an analysis of more specific or detailed components of exercise interventions investigated in a small number of trials, such as t' ai chi, which was classified as "predominantly strength and flexibility." We considered adding categories (such as balance or relaxation) or investigating t'ai chi separately, but this further complicated the analysis and strongly reduced the statistical power of the network meta-analysis.

As with most meta-analyses on exercise for osteoarthritis, our network meta-analysis could be criticised for including trials with varying length of follow-up periods. The different length of follow-up periods might have introduced some heterogeneity into the network meta-analysis. Methods that allow for repeated follow-up measurements have been reported for pairwise meta-analyses. The Cochrane handbook ${ }^{28}$ makes several recommendations for the meta-analysis of trials that report multiple time points, including the use of individual patient data meta-analysis and assessment of one particular time point. Methods that allow for inclusion of all time points in a network meta-analysis, however, are still under development. The choice of method will depend on the research question of interest and the data available from the included studies. None of these methods is free from biases. We explored the influence of differences in the duration of follow-up using meta-regression analysis, which did not result in significant or substantial differences in effect estimates. We could also have explored the potential influence of characteristics of the study population (such as mean age, severity of osteoarthritis), but meta-regression has low power in detecting patient level covariate effects when average study level covariate values are used. ${ }^{110-112}$ Similarly, it is prone to aggregation bias, a problem that can be avoided only with individual patient data meta-analysis. ${ }^{110-112} \mathrm{~A}$ final limitation is that we focused our review on clinical effectiveness only; we did not attempt to assess the cost effectiveness of preferentially using a particular exercise intervention.

\section{Comparison with other studies}

Several systematic reviews (including three recent Cochrane reviews) have concluded that exercise is beneficial for patients with osteoarthritis of the lower limb. ${ }^{813-21}$ Fransen and colleagues included 32 trials comparing any exercise intervention with a control group for knee osteoarthritis and showed that land based therapeutic exercise had significant benefits in terms of pain (SMD 0.40, 95\% confidence interval 0.30 to 0.50 ) and function $(0.37,0.25$ to 0.49$) .{ }^{13}$ The authors found no significant differences in the magnitude of treatment effects between difference types of exercise interventions. In another review, Fransen and colleagues included five trials and found a small treatment effect for pain but no benefit in terms of function for hip osteoarthritis. ${ }^{8}$ They cautioned that the results of the meta-analysis should be considered inconclusive because of the small number of trials and marked heterogeneity. ${ }^{8}$ Bartels and colleagues included six trials investigating aquatic exercise interventions and found a small to moderate effect on function (SMD 0.26, 95\% confidence interval 0.11 to 0.42 ) and large effect on pain $(0.86,0.25$ to 1.47$)$ for combined hip and knee osteoarthritis. ${ }^{15}$ The authors emphasised that caution is needed in recommending aquatic exercise interventions because of the limited number of trials in the meta-analysis and suggested that trials with clearly defined patient groups with long term outcomes are needed to further test aquatic exercise. ${ }^{15}$ Contrary to previous meta-analyses that concluded no clear superiority of one form of exercise over another in improving pain and function, ${ }^{13} 1418$ our study provides new, though tentative, evidence about the most effective exercise interventions for patients with lower limb osteoarthritis. It should be noted that most trials included in this meta-analysis focused on participants with knee osteoarthritis, and the results are therefore more applicable to such patients. The sensitivity analysis, which 
included only trials in knee osteoarthritis, showed slightly larger effect estimates compared with the overall analysis, regardless of the type of exercise. Once further evidence has accumulated about the role of exercise in hip osteoarthritis, a similar network meta-analysis might provide insight into the relative effectiveness of different types of exercise interventions in such patients.

\section{Implications for practice}

We believe our findings are both clinically and scientifically important. They suggest that some exercise interventions are likely to be more effective than others in helping achieve improvements in pain and function in patients with lower limb osteoarthritis. Exercise programmes that combine strengthening exercise with exercise aimed at increasing flexibility and aerobic capacity seem to be the "best" exercise option that clinicians can offer to patients. Current guidelines for osteoarthritis, such as those in the UK, ${ }^{1}$ report there is limited evidence for the benefits of one type of exercise over another and recommend both strengthening and aerobic exercise as "core" treatment. Osteoarthritis Research and Society International (OARSI) also recommended that osteoarthritis patients should be encouraged to undertake regular aerobic, muscle strengthening, and range of motion exercises. ${ }^{1213}$ The results of our study provide evidence to support this recommendation.

\section{Implications for research}

One paper cannot deal with all questions pertinent to the evaluation of exercise for lower limb osteoarthritis. With respect to further empirical trials, research is needed to better identify how best to support patients with lower limb osteoarthritis to adhere to exercise and physical activity, which patients with lower limb osteoarthritis benefit most from exercise, and whether some modes of delivery and support of exercise lead to better outcomes. Additional questions include determining the long term clinical and cost effectiveness of exercise interventions for lower limb osteoarthritis and how best to ensure that the beneficial short term effects of exercise are maintained over time.

We thank Mark Porcheret for his advice during the preparation of this paper and Kelvin Jordan for critical reading of this manuscript.

Contributors: OAU, DAvdW, JLJ, KSD, ELH, and NEF were responsible for study concept and design, acquisition of data, and analysis and interpretation of data. All authors drafted or wrote the manuscript and critically revised it for important intellectual content. OAU, DAvdW, and JLJ were responsible for statistical analysis. DAvdW, KSD, and NEF supervised the study. OAU is guarantor.

Funding: This study was funded by the National Institute for Health Research (NIHR) under its programme grants for applied research programme (grant reference No RP-PG-0407-10386). The NIHR had no role in the conduct of the study; collection, management, analysis, and interpretation of the data; and preparation, review of the manuscript. The conclusions and views expressed in this article are those of the authors and not necessarily those of the NHS, NIHR, or Department of Health.

Competing interests: All authors have completed the ICMJE uniform disclosure form at www.icmje.org/coi_disclosure.pdf (available on request from the corresponding author) and declare: DAvdW, KSD, $\mathrm{ELH}, \mathrm{GMP}$, and NEF are involved in the design and conduct of publicly funded trials on the effectiveness or exercise approaches for osteoarthritis or other musculoskeletal conditions.

Ethical approval: Not required.

Data sharing: No additional data available.
National Collaborating Centre for Chronic Conditions. Osteoarthritis: national clinical guideline for care and management in adults. Royal College of Physicians, 2008.

2 Murphy LB, Helmick CG, Schwartz TA, Renner JB, Tudor G, Koch GG, et al. One in four people may develop symptomatic hip osteoarthritis in his or her lifetime. Osteoarthritis Cartilage 2010;18:1372-9.

3 Murphy L, Schwartz TA, Helmick CG, Renner JB, Tudor G, Koch G, et al. Lifetime risk of symptomatic knee osteoarthritis. Arthritis Rheum 2008:59:1207-13.

4 DiBonaventura MD, Gupta S, McDonald M, Sadosky A, Pettitt D, Silverman S. Impact of self-rated osteoarthritis severity in an employed population: cross-sectional analysis of data from the national health and wellness survey. Health Qual Life Outcomes 2012;10:30.

5 Le TK, Montejano LB, Cao Z, Zhao Y, Ang D. Healthcare costs associated with osteoarthritis in US patients. Pain Pract 2012;12:633-40.

6 United States Bone and Joint Initiative. The burden of musculoskeletal diseases in the United States. 2nd ed. American Academy of Orthopaedic Surgeons, 2011. www. boneandjointburden.org/.

7 Gupta S, Hawker GA, Laporte A, Croxford R, Coyte PC. The economic burden of disabling hip and knee osteoarthritis $(\mathrm{OA})$ from the perspective of individuals living with this condition. Rheumatology (Oxford) 2005;44:1531-7.

8 Fransen M, McConnell S, Hernandez-Molina G, Reichenbach S. Exercise for osteoarthritis of the hip. Cochrane Database Syst Rev 2009;3:CD007912.

9 Rannou F, Poiraudeau S. Non-pharmacological approaches for the treatment of osteoarthritis. Best Pract Res Clin Rheumatol 2010;24:93-106.

10 Roddy E, Zhang W, Doherty M, Arden NK, Barlow J, Birrell F, et al. Evidence-based recommendations for the role of exercise in the management of osteoarthritis of the hip or knee-the MOVE consensus. Rheumatology (Oxford) 2005;44:67-73.

11 Zhang W, Doherty M, Arden N, Bannwarth B, Bijlsma J, Gunther KP, et al, EULAR Standing Committee for International Clinical Studies Including Therapeutics (ESCISIT). EULAR evidence based recommendations for the management of hip osteoarthritis: report of a task force of the EULAR Standing Committee for International Clinical Studies Including Therapeutics (ESCISIT). Ann Rheum Dis 2005;64:669-81.

12 Zhang W, Nuki G, Moskowitz RW, Abramson S, Altman RD, Arden NK, et al. OARSI recommendations for the management of hip and knee osteoarthritis: part III: Changes in evidence following systematic cumulative update of research published through January 2009. Osteoarthritis Cartilage 2010;18:476-99.

13 Fransen M, McConnell S. Exercise for osteoarthritis of the knee. Cochrane Database Syst Rev 2008;4:CD004376.

14 Bennell KL, Hinman RS. A review of the clinical evidence for exercise in osteoarthritis of the hip and knee. J Sci Med Sport 2011:14:4-9.

15 Bartels EM, Lund H, Hagen KB, Dagfinrud H, Christensen R, Danneskiold-Samsoe B. Aquatic exercise for the treatment of knee and hip osteoarthritis. Cochrane Database Syst Rev 2007;4:CD005523.

16 Iwamoto J, Sato Y, Takeda T, Matsumoto H. Effectiveness of exercise for osteoarthritis of the knee: a review of the literature. World J Orthop 2011;2:37-42.

17 Escalante Y, Garcia-Hermoso A, Saavedra JM. Effects of exercise on functional aerobic capacity in lower limb osteoarthritis: a systematic review. J Sci Med Sport2011:14:190-8.

18 Escalante Y, Saavedra JM, García-Hermoso A, Silva AJ, Barbosa TM. Physical exercise and reduction of pain in adults with lower limb osteoarthritis: a systematic review. J Back Musculoskelet Rehabil 2010;23:175-86.

19 Fransen M, McConnell S. Land-based exercise for osteoarthritis of the knee: a metaanalysis of randomized controlled trials. J Rheumatol 2009;36:1109-17.

20 Fransen M, McConnell S, Hernandez-Molina G, Reichenbach S. Does land-based exercise reduce pain and disability associated with hip osteoarthritis? A meta-analysis of randomized controlled trials. Osteoarthritis Cartilage 2010;18:613-20.

21 Wang TJ, Belza B, Elaine Thompson F, Whitney JD, Bennett K. Effects of aquatic exercise on flexibility, strength and aerobic fitness in adults with osteoarthritis of the hip or knee. $J$ Adv Nurs 2007;57:141-52.

22 Centre for Reviews and Dissemination. Acupuncture and other physical treatments for the relief of chronic pain due to osteoarthritis of the knee: a systematic review and network meta-analysis. University of York. CRD Report 40, 2012.

23 Altman RD. The classification of osteoarthritis. J Rheumatol Suppl 1995;43:42-3.

24 Bellamy N, Kirwan J, Boers M, Brooks P, Strand V, Tugwell P, et al. Recommendations for a core set of outcome measures for future phase III clinical trials in knee, hip, and hand osteoarthritis. Consensus development at OMERACT III. J Rheumatol 1997;24:799-802.

25 Higgins JP, Altman DG, Gøtzsche PC, Jüni P, Moher D, Oxman AD, et al; Cochrane Bias Methods Group; Cochrane Statistical Methods Group. The Cochrane Collaboration's tool for assessing risk of bias in randomised trials. BMJ 2011;343:d5928.

26 Hozo SP, Djulbegovic B, Hozo I. Estimating the mean and variance from the median, range, and the size of a sample. BMC Med Res Methodol 2005:5:13.

27 Jüni P, Reichenbach S, Dieppe P. Osteoarthritis: rational approach to treating the individual. Best Pract Res Clin Rheumatol 2006;20:721-40.

28 Deeks JJ, Higgins J, Altman DG. Analysing data and undertaking meta-analyses In: Higgins JPT, Green S, eds. Cochrane Handbook for Systematic Reviews of Interventions. Version 5.1.0. Cochrane Collaboration, 2011.

29 Artus M, van der Windt DA, Jordan KP, Hay EM. Low back pain symptoms show a simila pattern of improvement following a wide range of primary care treatments: a systematic review of randomized clinical trials. Rheumatology (Oxford) 2010;49:2346-56.

30 Cohen J. Statistical power analysis for the behavioral sciences. Lawrence Earlbaum Associates, 1988

31 Nüesch E, Trelle S, Reichenbach S, Rutjes AW, Bürgi E, Scherer M, et al. The effects of excluding patients from the analysis in randomised controlled trials: meta-epidemiological study. BMJ 2009;339:b3244.

32 Bellamy N. Outcome measurement in osteoarthritis clinical trials. J Rheumatol Suppl 1995;43:49-51.

33 Brok J, Thorlund K, Gluud C, Wetterslev J. Trial sequential analysis reveals insufficient information size and potentially false positive results in many meta-analyses. $J$ Clin Epidemiol 2008:61:763-9.

34 Higgins JP, Whitehead A, Simmonds M. Sequential methods for random-effects meta-analysis. Stat Med 2011;30:903-21.

35 Wetterslev J, Thorlund K, Brok J, Gluud C. Estimating required information size by quantifying diversity in random-effects model meta-analyses. BMC Med Res Methodo 2009;9:86.

36 Pogue JM, Yusuf S. Cumulating evidence from randomized trials: utilizing sequential monitoring boundaries for cumulative meta-analysis. Control Clin Trials Dec 1997; 18:580-93. 


\section{What is already known on this topic}

Current international guidelines recommend therapeutic exercise (land or water based) as "core" and effective management of osteoarthritis, given existing evidence regarding the beneficial effects of exercise on pain and function, ease of application, few adverse effects, and relatively low costs

\section{What this study adds}

As of the year 2002, there was enough evidence to show significant benefit of exercise interventions versus no exercise in lower limb osteoarthritis, indicating that further trials of exercise versus no exercise are unlikely to overturn this positive result Evidence from the network meta-analysis, largely based on studies in knee osteoarthritis, indicates that a programme combining flexibility strengthening, and aerobic exercise is most likely to improve outcomes of pain and function

37 Thorlund K, Engstrom J, Wetterslev J, Brok J, Imberger G, Gluud C. User manual for trial sequential analysis (TSA). Copenhagen Trial Unit, Centre for Clinical Intervention Research, 2011. www.ctu.dk/tsa.

38 Caldwell DM, Ades AE, Higgins JP. Simultaneous comparison of multiple treatments: combining direct and indirect evidence. BMJ 2005;331:897-900

$39 \mathrm{Lu} \mathrm{G}$, Ades AE. Combination of direct and indirect evidence in mixed treatment comparisons. Stat Med 2004;23:3105-24.

40 Salanti G, Ades AE, loannidis JP. Graphical methods and numerical summaries for presenting results from multiple-treatment meta-analysis: an overview and tutorial. J Clin Epidemiol 2011;64:163-71

41 Salanti G, Higgins JP, Ades AE, loannidis JP. Evaluation of networks of randomized trials. Stat Methods Med Res 2008;17:279-301.

42 Spiegelhalter D, Thomas A, Best N, Lunn D. WinBUGS user manual: version 1.4. MRC Biostatistics Unit, 2003.

43 Salanti G, Marinho V, Higgins JP. A case study of multiple-treatments meta-analysis demonstrates that covariates should be considered. J Clin Epidemiol 2009;62:857-64.

44 Krahn U, Binder $\mathrm{H}$, König J. A graphical tool for locating inconsistency in network meta-analyses. BMC Med Res Methodol 2013;13:35.

45 Dias S, Sutton A, Welton N, Ades AE. Heterogeneity, subgroups, meta-regression, bias and bias adjustment. NICE DSU technical support document 3. (last updated April 2012). NICE Decision Support Unit, 2011

46 Gelman A, Rubin DB. Inferences from iterative simulation using multiple sequences. Stat Sci 1992;7:457-511.

47 Brooks SP, Gelman A. Alternative methods for monitoring convergence of iterative simulations. J Comput Graph Stat 1998;7:434-55.

48 Aglamis B, Toraman NF, Yaman H. The effect of a 12-week supervised multicomponent exercise program on knee OA in Turkish women. J Back Musculoskeletal Rehabil 2008;21:121-9.

49 Aoki O, Tsumura N, Kimura A, Okuyama S, Takikawa S, Hirata S. Home stretching exercise is effective for improving knee range of motion and gait in patients with kne osteoarthritis. J Phys Ther Sci 2009;21:113-20.

50 Baker KR, Nelson ME, Felson DT, Layne JE, Sarno R, Roubenoff R. The efficacy of home based progressive strength training in older adults with knee osteoarthritis: a randomized controlled trial. J Rheumatol 2001;28:1655-65.

51 Bautch JC, Malone DG, Vailas AC. Effects of exercise on knee joints with osteoarthritis: a pilot study of biologic markers. Arthritis Care Res 1997;10:48-55

52 Bennell KL, Hinman RS, Metcalf BR, Buchbinder R, McConnell J, McColl G, et al. Efficacy of physiotherapy management of knee joint osteoarthritis: a randomised, double blind, placebo controlled trial. Ann Rheum Dis 2005:64:906-12.

53 Bennell KL, Hunt MA, Wrigley TV, Hunter DJ, McManus FJ, Hodges PW, et al. Hip strengthening reduces symptoms but not knee load in people with medial knee osteoarthritis and varus malalignment: a randomised controlled trial. Osteoarthritis Cartilage 2010;18:621-8.

54 Börjesson M, Robertson E, Weidenhielm L, Mattsson E, Olsson E. Physiotherapy in knee osteoarthrosis: effect on pain and walking. Physiother Res Int 1996:1:89-97.

55 Brismée JM, Paige RL, Chyu MC, Boatright JD, Hagar JM, McCaleb JA, et al. Group and home-based tai chi in elderly subjects with knee osteoarthritis: a randomized controlled trial. Clin Rehabil 2007;21:99-111.

56 Chaipinyo K, Karoonsupcharoen $\mathrm{O}$. No difference between home-based strength training and home-based balance training on pain in patients with knee osteoarthritis: a randomised trial. Aust J Physiother 2009:55:25-30.

57 Cochrane T, Davey RC, Matthes Edwards SM. Randomised controlled trial of the cost-effectiveness of water-based therapy for lower limb osteoarthritis. Health Technol Assess 2005;9:iii-iv, ix-xi, 1-114

58 Dias RC, Dias JM, Ramos LR. Impact of an exercise and walking protocol on quality of life for elderly people with OA of the knee. Physiother Res Int 2003;8:121-30.

59 Ettinger WH Jr, Burns R, Messier SP, Applegate W, Rejeski WJ, Morgan T, et al. A randomized trial comparing aerobic exercise and resistance exercise with a health education program in older adults with knee osteoarthritis. The Fitness Arthritis and Seniors Trial (FAST). JAMA 1997;277:25-31.

60 Farr JN, Going SB, McKnight PE, Kasle S, Cussler EC, Cornett M. Progressive resistance training improves overall physical activity levels in patients with early osteoarthritis of the knee: a randomized controlled trial. Phys Ther 2010;90:356-66.

61 Foley A, Halbert J, Hewitt T, Crotty M. Does hydrotherapy improve strength and physical function in patients with osteoarthritis-a randomised controlled trial comparing a gym based and a hydrotherapy based strengthening programme. Ann Rheum Dis 2003;62:1162-7.

62 Fransen M, Crosbie J, Edmonds J. Physical therapy is effective for patients with osteoarthritis of the knee: a randomized controlled clinical trial. $J$ Rheumatol 2001;28:156-64.

63 Fransen M, Nairn L, Winstanley J, Lam P, Edmonds J. Physical activity for osteoarthritis management: a randomized controlled clinical trial evaluating hydrotherapy or Tai $\mathrm{Chi}$ classes. Arthritis Rheum 2007;57:407-14

64 Gill SD, McBurney H, Schulz DL. Land-based versus pool-based exercise for people awaiting joint replacement surgery of the hip or knee: results of a randomized controlled trial. Arch Phys Med Rehabil 2009;90:388-94.
65 Gür H, Cakin N, Akova B, Okay E, Küçükoğlu S. Concentric versus combined concentric-eccentric isokinetic training: effects on functional capacity and symptoms in patients with osteoarthrosis of the knee. Arch Phys Med Rehabil 2002;83:308-16.

66 Halbert J, Crotty M, Weller D, Ahern M, Silagy C. Primary care-based physical activity programs: effectiveness in sedentary older patients with osteoarthritis symptoms. Arthritis Rheum 2001;45:228-34.

67 Hale LA, Waters D, Herbison P. A randomized controlled trial to investigate the effects of water-based exercise to improve falls risk and physical function in older adults with lower-extremity osteoarthritis. Arch Phys Med Rehabil 2012:93:27-34.

68 Hartman CA, Manos TM, Winter C, Hartman DM, Li B, Smith JC. Effects of T'ai Chi training on function and quality of life indicators in older adults with osteoarthritis. J Am Geriatr Soc 2000;48:1553-9.

69 Hay EM, Foster NE, Thomas E, Peat G, Phelan M, Yates HE, et al. Effectiveness of community physiotherapy and enhanced pharmacy review for knee pain in people aged over 55 presenting to primary care: pragmatic randomised trial. BMJ 2006:333:995-6.

70 Hinman RS, Heywood SE, Day AR. Aquatic physical therapy for hip and knee osteoarthritis: results of a single-blind randomized controlled trial. Phys Ther 2007;87:32-43.

71 Hopman-Rock M, Westhoff MH. The effects of a health educational and exercise program for older adults with osteoarthritis for the hip or knee. $J$ Rheumatol 2000;27:1947-54.

72 Huang MH, Lin YS, Yang RC, Lee CL. A comparison of various therapeutic exercises on the functional status of patients with knee osteoarthritis. Semin Arthritis Rheum 2003:32:398-406.

73 Huang MH, Lin YS, Lee CL, Yang RC. Use of ultrasound to increase effectiveness of isokinetic exercise for knee osteoarthritis. Arch Phys Med Rehabil 2005;86:1545-5

74 Hughes SL, Seymour RB, Campbell RT, Huber G, Pollak N, Sharma L, et al. Long-term impact of Fit and Strong! on older adults with osteoarthritis. Gerontologist 2006:46:801-14.

75 Hurley MV, Walsh NE, Mitchell HL, Pimm TJ, Patel A, Williamson E, et al. Clinical effectiveness of a rehabilitation program integrating exercise, self-management, and active coping strategies for chronic knee pain: a cluster randomized trial. Arthritis Rheum 2007;57:1211-9.

76 Keefe FJ, Blumenthal J, Baucom D, Affleck G, Waugh R, Caldwell DS, et al. Effects of spouse-assisted coping skills training and exercise training in patients with osteoarthritic knee pain: a randomized controlled study. Pain 2004;110:539-49.

77 Kovar PA, Allegrante JP, MacKenzie CR, Peterson MG, Gutin B, Charlson ME. Supervised fitness walking in patients with osteoarthritis of the knee. A randomized, controlled trial. Ann Intern Med 1992;116:529-34.

78 Lee HJ, Park HJ, Chae Y, Kim SY, Kim SN, Kim ST, et al. Tai Chi Qigong for the quality of life of patients with knee osteoarthritis: a pilot, randomized, waiting list controlled trial. Clin Rehabil 2009;23:504-11.

79 Lim JY, Tchai E, Jang SN. Effectiveness of aquatic exercise for obese patients with knee osteoarthritis: a randomized controlled trial. PM R 2010;2:723-31.

80 Lin DH, Lin CH, Lin YF, Jan MH. Efficacy of 2 non-weight-bearing interventions, proprioception training versus strength training, for patients with knee osteoarthritis: a randomized clinical trial. J Orthop Sports Phys Ther 2009;39:450-7.

81 Lund $\mathrm{H}$, Weile U, Christensen R, Rostock B, Downey A, Bartels EM, et al A randomized controlled trial of aquatic and land-based exercise in patients with knee osteoarthritis. $J$ Rehabil Med 2008;40:137-44.

82 McCarthy CJ, Pullen R, Mills PM, Roberts CR, Silman AJ, Oldham JA. Supplementing home exercise with class-based exercise is more effective than home exercise alone in reducing pain and increasing function in patients with knee osteoarthritis: results from a randomised clinical trial. Arthritis Rheum 2002;46:S143.

83 Messier SP, Loeser RF, Miller GD, Morgan TM, Rejeski WJ, Sevick MA, et al. Exercise and dietary weight loss in overweight and obese older adults with knee osteoarthritis: the Arthritis, Diet, and Activity Promotion Trial. Arthritis Rheum 2004;50:1501-10.

84 Mikesky AE, Mazzuca SA, Brandt KD, Perkins SM, Damush T, Lane KA. Effects of strength training on the incidence and progression of knee osteoarthritis. Arthritis Rheum 2006;55:690-9.

85 Minor MA, Hewett JE, Webel RR, Anderson SK, Kay DR. Efficacy of physical conditioning exercise in patients with rheumatoid arthritis and osteoarthritis. Arthritis Rheum 1989;32:1396-405

86 O'Reilly SC, Muir KR, Doherty M. Effectiveness of home exercise on pain and disability from osteoarthritis of the knee: a randomised controlled trial. Ann Rheum Dis 1999;58:15-9.

87 Patrick DL, Ramsey SD, Spencer AC, Kinne S, Belza B, Topolski TD. Economic evaluation of aquatic exercise for persons with osteoarthritis. Med Care 2001;39:413-24.

88 Péloquin L, Bravo G, Gauthier P, Lacombe G, Billiard JS. Effects of a cross-training exercise program in persons with osteoarthritis of the knee a randomized controlled trial. $J$ Clin Rheumatol 1999;5:126-36.

89 Quilty B, Tucker M, Campbell R, Dieppe P. Physiotherapy, including quadriceps exercises and patellar taping, for knee osteoarthritis with predominant patello-femoral joint involvement: randomized controlled trial. $J$ Rheumatol 2003:30:1311-7.

90 Ravaud P, Giraudeau B, Logeart I, Larguier JS, Rolland D, Treves R, et al. Management of osteoarthritis (OA) with an unsupervised home based exercise programme and/or patient administered assessment tools. A cluster randomised controlled trial with a $2 \times 2$ factorial design. Ann Rheum Dis 2004;63:703-8.

91 Rogind H, BibowNeilsen B, Jensen B, Moller HC, FrimodtMoller H, Bliddal H. The effects of a physical training program on patients with osteoarthritis of the knees. Arch Phys Med Rehabil 1998;79:1421-7. 
92 Salli A, Sahin N, Baskent A, Ugurlu $\mathrm{H}$. The effect of two exercise programs on various functional outcome measures in patients with osteoarthritis of the knee: A randomized controlled clinical trial. Isokinet Exerc Sci 2010;18:201-10.

93 Schilke JM, Johnson GO, Housh TJ, O'Dell JR. Effects of muscle-strength training on the functional status of patients with osteoarthritis of the knee joint. Nurs Res 1996;45:68-72.

94 Silva LE, Valim V, Pessanha AP, Oliveira LM, Myamoto S, Jones A, et al. Hydrotherapy versus conventional land-based exercise for the management of patients with osteoarthritis of the knee: a randomized clinical trial. Phys Ther 2008:88:12-21.

95 Song F, Xiong T, Parekh-Bhurke S, Loke YK, Sutton AJ, Eastwood AJ, et al. Inconsistency between direct and indirect comparisons of competing interventions: meta-epidemiological study. BMJ 2011;343:d4909.

96 Stener-Victorin E, Kruse-Smidje C, Jung K, StenerVictorin E. Comparison between electro-acupuncture and hydrotherapy, both in combination with patient education and patient education alone, on the symptomatic treatment of osteoarthritis of the hip. Clin $J$ Pain 2004;20:179-85.

97 Tak E, Staats P, Van Hespen A, Hopman-Rock M. The effects of an exercise program for older adults with osteoarthritis of the hip. J Rheumatol 2005;32:1106-13

98 Talbot LA, Gaines JM, Huynh TN, Metter EJ. A home-based pedometer-driven walking program to increase physical activity in older adults with osteoarthritis of the knee: a preliminary study. J Am Geriatr Soc 2003:51:387-92.

99 Thomas KS, Muir KR, Doherty M, Jones AC, O’Reilly SC, Bassey EJ. Home based exercise programme for knee pain and knee osteoarthritis: randomised controlled trial. BMJ 2002;325:752

100 Thorstensson CA, Roos EM, Petersson IF, Ekdahl C. Six-week high-intensity exercise program for middle-aged patients with knee osteoarthritis: a randomized controlled trial. BMC Musculoskelet Disord 2005:6:27.

101 Topp R, Woolley S, Hornyak J 3rd, Khuder S, Kahaleh B. The effect of dynamic versus isometric resistance training on pain and functioning among adults with osteoarthritis of the knee. Arch Phys Med Rehabil 2002;83:1187-95.

102 Van Baar ME, Dekker J, Oostendorp RA, Bijl D, Voorn TB, Bijlsma JW. Effectiveness of exercise in patients with osteoarthritis of hip or knee: nine months' follow up. Ann Rheum Dis 2001;60:1123-30.

103 Wang C, Schmid CH, Hibberd PL, Kalish R, Roubenoff R, Rones R, et al. Tai Chi is effective in treating knee osteoarthritis: a randomized controlled trial. Arthritis Rheum 2009;61:1545-53

104 Wang TJ, Lee SC, Liang SY, Tung HH, Wu SF, Lin YP. Comparing the efficacy of aquatic exercises and land-based exercises for patients with knee osteoarthritis. J Clin Nurs 2011;20:2609-22.
105 Weng MC, Lee CL, Chen CH, Hsu JJ, Lee WD, Huang MH, et al. Effects of different stretching techniques on the outcomes of isokinetic exercise in patients with knee osteoarthritis. Kaohsiung J Med Sci 2009;25:306-15.

106 Williamson L, Wyatt MR, Yein K, Melton JT. Severe knee osteoarthritis: a randomized controlled trial of acupuncture, physiotherapy (supervised exercise) and standard management for patients awaiting knee replacement. Rheumatology (Oxford) 2007;46:1445-9

107 Yennan P, Suputtitada A, Yuktanandana P. Effects of aquatic exercise and land-based exercise on postural sway in elderly with knee osteoarthritis. Asian Biomedicine 2010;4:739-45.

108 Van der Tweel I, Bollen C. Sequential meta-analysis: an efficient decision-making tool. Clin Trials 2010;7:136-46.

109 Cooper NJ, Kendrick D, Achana F, Dhiman P, He Z, Wynn P, et al. Network meta-analysis to evaluate the effectiveness of interventions to increase the uptake of smoke alarms. Epidemiol Rev 2011;34:32-45

110 Lambert PC, Sutton AJ, Abrams KR, Jones DR. A comparison of summary patient-level covariates in meta-regression with individual patient data meta-analysis. J Clin Epidemio 2002;55:86-94.

111 Schmid CH, Stark PC, Berlin JA, Landais P, Lau J. Meta-regression detected associations between heterogeneous treatment effects and study-level, but not patient-level, factors. J Clin Epidemiol 2004;57:683-97.

112 Thompson SG, Higgins JP. How should meta-regression analyses be undertaken and interpreted? Stat Med 2002;21:1559-73.

113 Zhang W, Moskowitz RW, Nuki G, Abramson S, Altman RD, Arden N, et al. OARS recommendations for the management of hip and knee osteoarthritis, Part II: OARSI evidence-based, expert consensus guidelines. Osteoarthritis Cartilage 2008;16:137-62.

Accepted: 16 August 2013

\section{Cite this as: BMJ 2013;347:f5555}

This is an Open Access article distributed in accordance with the Creative Commons Attribution Non Commercial (CC BY-NC 3.0) license, which permits others to distribute, remix, adapt, build upon this work non-commercially, and license their derivative works on different terms, provided the original work is properly cited and the use is non-commercial. See: http://creativecommons.org/licenses/by-nc/3.0/. 


\section{Tables}

Table 1 | Statistical heterogeneity $\left(I^{2}\right)$ for all pairwise comparisons in studies of exercise for treatment of lower limb osteoarthritis

\begin{tabular}{|c|c|c|c|c|}
\hline \multirow[b]{2}{*}{ Pairwise comparison } & \multicolumn{2}{|c|}{ Pain relief } & \multicolumn{2}{|c|}{ Physical function } \\
\hline & No of studies & $\mathrm{I}^{2}(\%)(95 \% \mathrm{Cl})$ & No of studies & $\mathrm{I}^{2}(\%)(95 \% \mathrm{Cl})$ \\
\hline \multicolumn{5}{|c|}{ Compared with no intervention } \\
\hline Flexibility & 2 & 0.0 & 1 & NA \\
\hline Strengthening & 16 & 91.5 (87.8 to 94.1$)$ & 16 & 91.9 (88.4 to 94.3$)$ \\
\hline Aerobic & 3 & $22.8(0.0$ to 92.0$)$ & 2 & $0.0(\mathrm{NA})$ \\
\hline Flexibility+strengthening & 11 & $90.6(85.3$ to 94.0$)$ & 10 & 86.1 (76.3 to 91.8$)$ \\
\hline Flexibility+aerobic & 3 & $0.0(0.0$ to 89.6$)$ & 3 & $0.0(0.0$ to 89.6$)$ \\
\hline Strengthening+aerobic & 3 & $65.9(0.0$ to 90.2$)$ & 3 & $0.0(0.0$ to 89.6$)$ \\
\hline Combined & 12 & 81.9 (69.5 to 89.2$)$ & 10 & 83.4 (70.9 to 90.5$)$ \\
\hline \multicolumn{5}{|l|}{ Aquatic: } \\
\hline Strengthening & 3 & $0.6(0.0$ to 89.7$)$ & 3 & $10.2(0.0$ to 90.7$)$ \\
\hline Flexibility+strengthening & 2 & 79.3 (NA) & 1 & NA \\
\hline Flexibility+aerobic & 2 & 72.1 (NA) & 2 & 23.6 (NA) \\
\hline Strengthening+aerobic & 1 & NA & 1 & NA \\
\hline Combined & 3 & $83.3(49.3$ to 94.5$)$ & 3 & $0.0(0.0$ to 89.6$)$ \\
\hline \multicolumn{5}{|l|}{ Compared with flexibility } \\
\hline Strengthening & 3 & 0.0 (0.0 to 89.6$)$ & 3 & $0.0(0.0$ to 89.6$)$ \\
\hline
\end{tabular}

Compared with strengthening

\begin{tabular}{lllll}
\hline Aerobic & 1 & NA & 1 & NA \\
\hline Flexibility+strengthening & 1 & NA & 1 & NA \\
\hline Aquatic: strengthening & 1 & NA & 1 & NA \\
\hline
\end{tabular}

\begin{tabular}{lcccc}
\hline Compared with flexibility+strengthening & & & \\
\hline Combined & 2 & 0.0 & 2 & 73.1 (NA) \\
\hline
\end{tabular}

\begin{tabular}{|c|c|c|c|c|}
\hline Combined & 2 & 0.0 & 2 & 73.1 (NA) \\
\hline \multicolumn{5}{|l|}{ Aquatic: } \\
\hline Strengthening & 1 & NA & 1 & NA \\
\hline Flexibility+strengthening & 2 & 80.8 & 2 & $0.0(\mathrm{NA})$ \\
\hline Combined & 1 & NA & 1 & NA \\
\hline \multicolumn{5}{|c|}{ Compared with flexibility+aerobic } \\
\hline Aquatic: flexibility+aerobic & 1 & NA & 1 & NA \\
\hline \multicolumn{5}{|l|}{ Compared with combined } \\
\hline \multicolumn{5}{|l|}{ Aquatic: } \\
\hline Strengthening+aerobic & 1 & NA & 1 & NA \\
\hline Combined & 3 & $33.0(0.0$ to 93.0$)$ & 3 & $0.0(0.0$ to 89.6$)$ \\
\hline
\end{tabular}

$\mathrm{NA}=$ not assessed. 
Table 2| Results of network meta-analysis of pain relief, without covariates, and additionally with adjustment for follow-up period, trial publication year, and number of sessions, with meta-regression. Figures are standardised mean difference (SMD) with $95 \%$ credible intervals and probability for cumulative ranking with surface under cumulative ranking (SUCRA)

\begin{tabular}{|c|c|c|c|c|}
\hline & \multicolumn{2}{|c|}{ No adjustment } & \multicolumn{2}{|c|}{ Covariates adjusted } \\
\hline & SMD $(95 \% \mathrm{Crl})$ & Prob (SUCRA) & SMD (95\% Crl) & Prob (SUCRA) \\
\hline \multicolumn{5}{|c|}{ Lower limb (knee, hips or multiple joints) } \\
\hline No intervention control & Reference & 11 & Reference & 12.2 \\
\hline Flexibility & $-0.66(-1.33$ to -0.00$)$ & 61.4 & $-0.62(-1.31$ to 0.07$)$ & 61.2 \\
\hline Strengthening & $-0.81(-1.13$ to -0.50$)$ & 76.3 & $-0.74(-1.09$ to -0.39$)$ & 73.4 \\
\hline Aerobic & $-0.41(-1.13$ to 0.30$)$ & 42.3 & $-0.33(-1.08$ to 0.40$)$ & 39.3 \\
\hline Flexibility+strengthening & $-0.50(-0.85$ to -0.16$)$ & 47.6 & $-0.45(-0.84$ to -0.06$)$ & 45.7 \\
\hline Flexibility+aerobic & $-0.26(-1.00$ to 0.47$)$ & 32.3 & $-0.22(-1.00$ to 0.56$)$ & 31.7 \\
\hline Strengthening+aerobic & $-0.13(-0.88$ to 0.61$)$ & 24.2 & $-0.26(-1.07$ to 0.56$)$ & 34.4 \\
\hline Combined & $-0.69(-1.04$ to -0.35$)$ & 65.9 & $-0.64(-1.04$ to -0.26$)$ & 64.9 \\
\hline \multicolumn{5}{|l|}{ Aquatic: } \\
\hline Strengthening & $-0.75(-1.42$ to -0.07$)$ & 67.6 & $-0.68(-1.38$ to 0.02$)$ & 65.1 \\
\hline Flexibility+strengthening & $-0.96(-1.64$ to -0.27$)$ & 81.3 & $-0.91(-1.62$ to -0.21$)$ & 80.9 \\
\hline Flexibility+aerobic & $-0.07(-0.98$ to 0.83$)$ & 22.7 & $0.01(-0.95$ to 0.97$)$ & 19.8 \\
\hline Strengthening+aerobic & $-0.92(-2.08$ to 0.25$)$ & 72.9 & $-0.87(-2.05$ to 0.31$)$ & 72.2 \\
\hline Combined & $-0.45(-1.02$ to 0.11$)$ & 44.5 & $-0.47(-1.09$ to 0.14$)$ & 49.1 \\
\hline Follow-up period & - & - & $-0.001(-0.009$ to 0.007$)$ & - \\
\hline Publication year† & - & - & $-0.011(-0.048$ to 0.025$)$ & - \\
\hline$\underline{\text { No of sessions } \ddagger}$ & - & - & $0.003(-0.002$ to 0.009$)$ & - \\
\hline \multicolumn{5}{|l|}{ Knee only } \\
\hline No intervention control & Reference & 11.9 & Reference & 12.6 \\
\hline Flexibility & $-0.74(-1.48$ to -0.00$)$ & 57.3 & $-0.70(-1.50$ to 0.09$)$ & 57.1 \\
\hline Strengthening & $-0.94(-1.31$ to -0.57$)$ & 72.8 & $-0.88(-1.31$ to -0.46$)$ & 71.2 \\
\hline Aerobic & $-0.43(-1.22$ to 0.35$)$ & 38.4 & $-0.38(-1.22$ to 0.46$)$ & 37.2 \\
\hline Flexibility+strengthening & $-0.63(-1.13$ to -0.12$)$ & 49.0 & $-0.54(-1.12$ to 0.04$)$ & 45.6 \\
\hline Flexibility+aerobic & $-0.33(-1.17$ to 0.50$)$ & 32.7 & $-0.30(-1.22$ to 0.60$)$ & 33.1 \\
\hline Strengthening+aerobic & $0.02(-0.99$ to 1.02$)$ & 17.5 & $-0.16(-1.42$ to 1.11$)$ & 28.9 \\
\hline Combined & $-0.79(-1.21$ to -0.38$)$ & 61.5 & $-0.74(-1.23$ to -0.25$)$ & 60.3 \\
\hline \multicolumn{5}{|l|}{ Aquatic: } \\
\hline Strengthening & - & - & - & - \\
\hline Flexibility+strengthening & $-1.25(-2.39$ to -0.11$)$ & 81.0 & $-1.17(-2.38$ to 0.04$)$ & 78.6 \\
\hline Flexibility+aerobic & $-0.42(-1.76$ to 0.92$)$ & 40.3 & $-0.39(-1.80$ to 1.03$)$ & 40.3 \\
\hline Strengthening+aerobic & $-0.97(-2.25$ to 0.32$)$ & 67.0 & $-0.92(-2.26$ to 0.43$)$ & 66.0 \\
\hline Combined & $-1.04(-2.33$ to 0.24$)$ & 70.6 & $-0.99(-2.33$ to 0.35$)$ & 69.2 \\
\hline Follow-up period & 一 & 一 & $-0.00(-0.010$ to 0.010$)$ & 一 \\
\hline Publication year & - & - & $-0.011(-0.054$ to 0.033$)$ & - \\
\hline No of sessions ${ }^{\cdots}$ & - & - & $0.002(-0.005$ to 0.010$)$ & - \\
\hline
\end{tabular}


Table 3| Results of network meta-analysis improvement of function, without covariates, and additionally with adjustment for follow-up period, trial publication year, and number of sessions, with meta-regression. Figures are standardised mean difference (SMD) with 95\% credible intervals and probability for cumulative ranking with surface under cumulative ranking (SUCRA)

\begin{tabular}{|c|c|c|c|c|}
\hline & \multicolumn{2}{|c|}{ No adjustment } & \multicolumn{2}{|c|}{ Covariates adjusted } \\
\hline & SMD (95\% Crl) & Prob (SUCRA) & SMD (95\% Crl) & Prob (SUCRA) \\
\hline \multicolumn{5}{|c|}{ Lower limb (knee, hips or multiple joints) } \\
\hline No intervention control & Reference & 22.7 & Reference & 23.5 \\
\hline Flexibility & $-0.17(-1.26$ to 0.93$)$ & 40.1 & $-0.14(-1.26$ to 0.97$)$ & 38.8 \\
\hline Strengthening & $-0.37(-0.84$ to 0.09$)$ & 52.8 & $-0.36(-0.87$ to 0.14$)$ & 52.1 \\
\hline Aerobic & $-0.30(-1.53$ to 0.92$)$ & 47.9 & $-0.46(-1.71$ to 0.80$)$ & 55.9 \\
\hline Flexibility+strengthening & $-0.40(-0.92$ to 0.12$)$ & 54.6 & $-0.38(-0.98$ to 0.22$)$ & 52.9 \\
\hline Flexibility+aerobic & $-0.18(-1.24$ to 0.89$)$ & 40.7 & $-0.27(-1.40$ to 0.86$)$ & 46.0 \\
\hline Strengthening+aerobic & $-0.17-1.25$ to 0.91$)$ & 40.0 & $-0.26(-1.46$ to 0.94$)$ & 45.6 \\
\hline Combined & $-0.63(-1.16$ to -0.10$)$ & 70.9 & $-0.57(-1.17$ to 0.03$)$ & 66.8 \\
\hline \multicolumn{5}{|l|}{ Aquatic: } \\
\hline Strengthening & $-0.43(-1.42$ to 0.56$)$ & 55.2 & $-0.34(-1.36$ to 0.68$)$ & 49.7 \\
\hline Flexibility+strengthening & $-0.61(-1.75$ to 0.52$)$ & 64.9 & $-0.57(-1.73$ to 0.58$)$ & 62.7 \\
\hline Flexibility+aerobic & $0.07(-1.23$ to 1.36$)$ & 29.5 & $0.13(-1.24$ to 1.50$)$ & 27.1 \\
\hline Strengthening+aerobic & $-0.86(-2.52$ to 0.79$)$ & 71.4 & $-0.79(-2.47$ to 0.90$)$ & 68.5 \\
\hline Combined & $-0.49(-1.32$ to 0.33$)$ & 59.5 & $-0.51(-1.40$ to 0.39$)$ & 60.3 \\
\hline Follow-up period & - & - & $0.009(-0.003$ to 0.021$)$ & - \\
\hline Publication year† & - & - & $-0.001(-0.056$ to 0.054$)$ & - \\
\hline No of sessions $\ddagger$ & - & - & $-0.000(-0.009$ to 0.008$)$ & - \\
\hline \multicolumn{5}{|l|}{ Knee only osteoarthritis } \\
\hline No intervention control & Reference & 23 & Reference & 22.4 \\
\hline Flexibility & $-0.22(-1.36$ to 0.92$)$ & 39.8 & $-0.23(-1.39$ to 0.93$)$ & 38.9 \\
\hline Strengthening & $-0.43(-0.94$ to 0.07$)$ & 51.6 & $-0.46(-1.02$ to 0.10$)$ & 51.5 \\
\hline Aerobic & $-0.32(-1.58$ to 0.94$)$ & 45.4 & $-0.54(-1.83$ to 0.75$)$ & 54.3 \\
\hline Flexibility+strengthening & $-0.65(-1.38$ to 0.07$)$ & 63.5 & $-0.73(-1.56$ to 0.11$)$ & 65.6 \\
\hline Flexibility+aerobic & $-0.21(-1.33$ to 0.91$)$ & 39.6 & $-0.32(-1.51$ to 0.87$)$ & 43.9 \\
\hline Strengthening+aerobic & $-0.08(-1.43$ to 1.28$)$ & 34.5 & $-0.08(-1.88$ to 1.72$)$ & 36.1 \\
\hline Combined & $-0.70(-1.32$ to -0.09$)$ & 67.1 & $-0.60(-1.28$ to 0.10$)$ & 58.9 \\
\hline \multicolumn{5}{|l|}{ Aquatic: } \\
\hline Strengthening & - & - & - & - \\
\hline Flexibility+strengthening & $-0.95(-2.51$ to 0.61$)$ & 71.3 & $-1.02(-2.63$ to 0.59$)$ & 72.7 \\
\hline Flexibility+aerobic & $-0.10(-1.89$ to 1.68$)$ & 37.6 & $-0.12(-1.94$ to 1.71$)$ & 37.4 \\
\hline Strengthening+aerobic & $-0.90(-2.61$ to 0.81$)$ & 68.2 & $-0.80(-2.55$ to 0.94$)$ & 63.6 \\
\hline Combined & $-0.64(-2.35$ to 1.08$)$ & 58.4 & $-0.57(-2.32$ to 1.17$)$ & 54.7 \\
\hline Follow-up period & - & - & $0.012(-0.002$ to 0.026$)$ & - \\
\hline Publication year† & - & - & $0.006(-0.055$ to 0.067$)$ & - \\
\hline No of sessions $\ddagger$ & - & - & $-0.003(-0.015$ to 0.009$)$ & - \\
\hline
\end{tabular}

*Follow-up period (in weeks) centred at mean value (27.8 weeks).

†Publication year centred at 2000 .

$\ddagger$ No of sessions centred at mean value (31.4 sessions). 


\section{Figures}

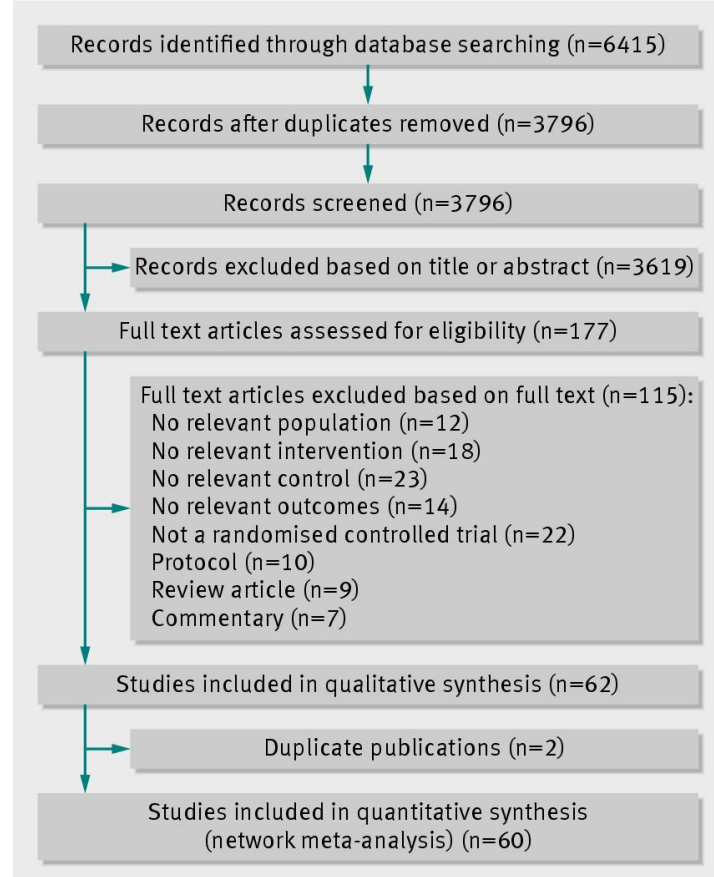

Fig 1 Study selection of trials examining exercise in treatment of lower limb osteoarthritis 


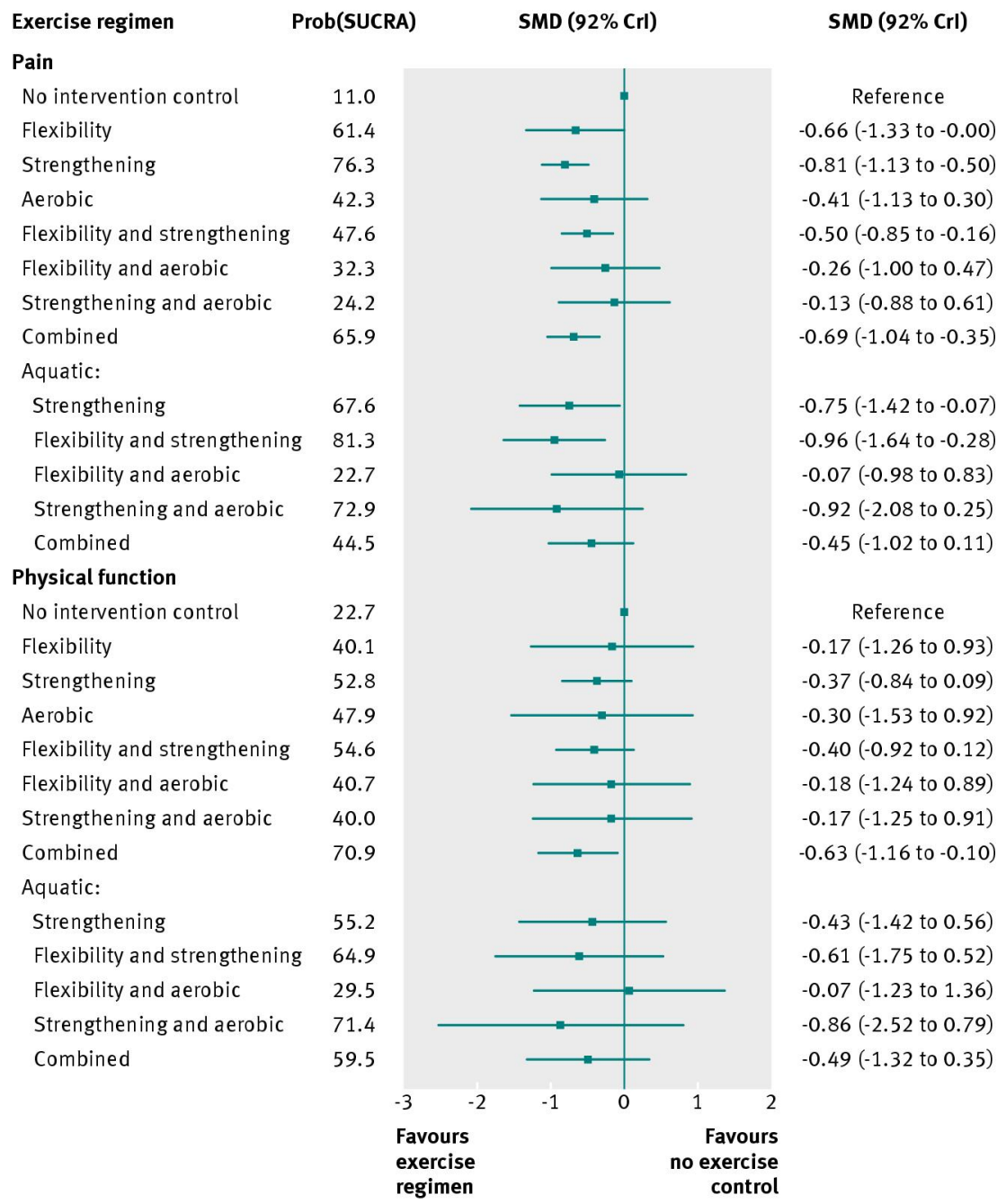

Fig 2 Forest plots for network meta-analysis for pain and physical function outcomes with no exercise as reference group. $\mathrm{SMD}=$ standardised mean difference, SUCRA=surface under cumulative ranking. SUCRA $=1$ when exercise intervention is certain to be best (that is, always ranks first) and 0 when exercise intervention is certain to be worst

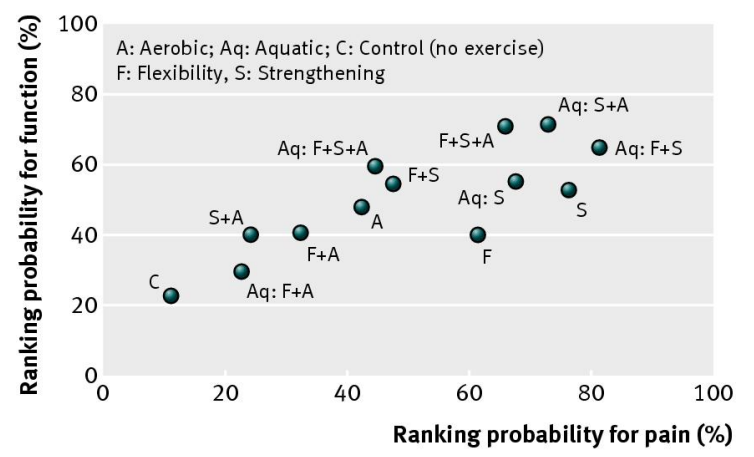

Fig 3 Scatter plot presenting ranking of exercise interventions for pain reduction and physical function based on cumulative probability of being most effective intervention 